OPEN ACCESS

Edited by: Zongbing You,

Tulane University, United States

Reviewed by: Jun Chen,

Tianjin Medical University General

Hospital, China

Jianjun Qin,

Chinese Academy of Medical Sciences \& Peking Union Medical

College, China

*Correspondence:

Guowei Che

cheguoweixw@126.com

${ }^{\dagger}$ These authors have contributed equally to this work

Specialty section:

This article was submitted to Surgical Oncology, a section of the journa

Frontiers in Oncology

Received: 24 September 2021 Accepted: 02 November 2021 Published: 22 November 2021

Citation:

Chang S, Zhou K, Wang Y, Lai $Y$ and Che $G$ (2021) Prognostic Value of Preoperative Peak Expiratory

Flow to Predict Postoperative

Pulmonary Complications in Surgical Lung Cancer Patients.

Front. Oncol. 11:782774. doi: 10.3389/fonc.2021.782774

\section{Prognostic Value of Preoperative Peak Expiratory Flow to Predict Postoperative Pulmonary Complications in Surgical Lung Cancer Patients}

\author{
Shuai Chang ${ }^{1 \dagger}$, Kun Zhou ${ }^{1,2 \dagger}$, Yan Wang ${ }^{1}$, Yutian Lai ${ }^{1,3}$ and Guowei Che ${ }^{1 *}$ \\ 1 Department of Thoracic Surgery, West China Hospital, Sichuan University, Chengdu, China, ${ }^{2}$ Department of Thoracic \\ Surgery, The First Affiliated Hospital, Zhejiang University School of Medicine, Hangzhou, China, ${ }^{3}$ Lung Cancer Center, \\ West China Hospital, Sichuan University, Chengdu, China
}

Objectives: Cough impairment may lead to excessive accumulation of pulmonary secretions and increase the risk of postoperative pulmonary complications (PPCs). Peak expiratory flow (PEF) is a sensitive indicator of cough ability. We aimed to investigate the correlation between PEF and PPCs for lung cancer patients undergoing lobectomy or segmental resection for improved risk assessment.

Methods: This retrospective study assessed 560 patients with non-small cell lung cancer admitted for surgery between January 2014 to June 2016. The measurements of PEF were performed before surgery and the clinical outcomes were recorded, including PPCs, postoperative hospital stay, hospitalization costs, and other variables.

Results: Preoperative PEF was significantly lower in PPCs group compared to non-PPCs group ( $294.2 \pm 95.7$ vs. $363.0 \pm 105.6 \mathrm{~L} / \mathrm{min}, \mathrm{P}<0.001)$. Multivariable regression analysis showed that high PEF (OR=0.991, 95\%Cl: 0.988-0.993, $\mathrm{P}<0.001)$ was an independent protective factor for PPCs. According to the receiver operating characteristic $(\mathrm{ROC})$ curve, a PEF value of $250 \mathrm{~L} / \mathrm{min}$ was selected as the optimal cutoff value in female patients, and $320 \mathrm{~L} / \mathrm{min}$ in male patients. Patients with PEF under cutoff value of either sex had higher PPCs rate and unfavorable clinical outcomes.

Conclusions: Preoperative PEF was found to be a significant predictor of PPCs for surgical lung cancer patients. It may be beneficial to consider the cutoff value of PEF in perioperative risk assessment.

Keywords: peak expiratory flow (PEF), postoperative pulmonary complications, lung neoplasms, pulmonary surgical procedures, pulmonary rehabilitation 


\section{INTRODUCTION}

Lung cancer continues to be the leading cause of cancer death worldwide and poses to be a threat to human health and economic burden (1). Surgical resection with lymph node dissection remains the optimal curative treatment for resectable lung cancer patients (2). However, surgery directly impairs postoperative respiratory function, and the incidence of postoperative pulmonary complications (PPCs) is as high as $19 \%-59 \%$ due to reasons such as reduced lung volume, weakened respiratory muscle strength and reduced cough efficiency (3). As a result, PPCs not only seriously affect the recovery of cardiopulmonary function, but also prolong the length of hospital stay and increase the cost of hospitalization. Consequently, PPC is one of the leading causes of postoperative death and treatment failure (4).

Several clinical studies have defined risk factors for PPC and consensus risk factors including advanced age, poor lung function status, smoking history, chronic obstructive pulmonary disease (COPD), American Society of Anesthesiologists (ASA) score $\geq 3$, and long duration of surgery (5-7). Complications such as postoperative pneumonia, atelectasis and pleural effusion resulting in PPC are mostly caused by the reduced efficiency of cough. As a consequence, this may result in excessive accumulation of pulmonary secretions, increasing the risk of airway obstruction and postoperative respiratory infection (8). Peak expiratory flow $(\mathrm{PEF})$ is usually defined as the maximum airflow rate that a person can exhale over a period of 10 milliseconds, which is a sensitive indicator of coughing ability, reflecting airway resistance and respiratory muscle strength (9). Thus, we hypothesized that preoperative PEF would be an effective indicator to predict PPCs that may arise in surgical lung cancer patients.

In the present study, we conducted a prospective cohort study to investigate the correlation between preoperative PEF and clinical outcomes in patients with lung cancer undergoing anatomic lobectomy or segmentectomy.

\section{MATERIALS AND METHODS}

\section{Population}

A total of 720 surgical lung cancer patients who underwent surgery by the same surgeon was collected in our unit between January 2014 to June 2016. Eligibility for this study were the patients who had a pathological diagnosis of non-small cell lung cancer (NSCLC) and underwent lung cancer anatomic lobectomy or segmentectomy, including open thoracotomy and video-assisted thoracoscopic surgery. Patients were excluded if they: (I) had preoperative signs of pulmonary infection, including purulent sputum or positive signs on sputum microbiology, temperature $>38^{\circ} \mathrm{C}$, leukocytosis before surgery; (II) had a history of antibiotic therapy within two weeks before surgery; and (III) had incomplete clinical data. Finally, 560 patients were enrolled in this study, including 104 patients who had PPCs and 456 patients without PPCs. Lung cancer was pathologically staged according to the International Union Against Cancer staging system (8th edition) (10). All patients received resection under general anesthesia and patient-controlled intravenous analgesia for postoperative pain control.

\section{Peak Expiratory Flow}

Prior to surgery, PEF was measured at the bedside with a portable peak flow meter. Patients took standing position and were instructed to inhale deeply, and then exhale as forcefully and quickly as possible. The patients need to complete at least 3 qualified measurements and the highest PEF value was recorded (the difference between the best two results should be within $20 \mathrm{~L} / \mathrm{min})$.

\section{Definition of PPCs}

PPCs, as defined earlier (11-13) included (I) pneumonia, chest radiological evidence of new or progressive pulmonary infiltrate and associated with at least one of the following: fever $\left(>38^{\circ} \mathrm{C}\right)$, purulent sputum, leukocytosis $\left(>12000 / \mathrm{mm}^{3}\right)$ or leukopenia $\left(<4000 / \mathrm{mm}^{3}\right)$, upgraded antibiotic class or extended use time (antibiotics are continued longer than 24 hours postoperatively); (II) atelectasis, part of the lung turns airless and contracts, diagnosed by chest X-ray within 24 hours after surgery; (III) prolonged air leak, postoperative air leak requiring chest tube drainage $>5$ days; (IV) pneumothorax, diagnosed by chest X-ray within 24 hours after surgery, air in the pleural space $>30 \%$, and requiring chest tube replacement; (V) pleural effusion, diagnosed by chest X-ray within 24 hours after surgery, pleural effusion requiring thoracocentesis; (VI) bronchospasm, newly detected expiratory wheezing treated with bronchodilators.; (VII) acute respiratory failure, requiring mechanical ventilation $>48 \mathrm{~h}$ or reintubation; (VIII) bronchopleural fistula, diagnosed by bronchoscopy; and (IX) pulmonary embolism, diagnosed by pulmo-nary CT angiography.

\section{Grouping Criterion}

First of all, the patients were categorized into those with and without PPC, according to whether they suffered PPCs. To distinguish the variables that correlated with PPCs, betweengroup comparisons were made. Secondly, the significant variables identified were then included in a multivariable logistic regression analysis to evaluate the independent risk factors of PPCs. Based on the above analysis results, we performed a receiver operating characteristic (ROC) analysis to determine the performance of PEF for predicting PPCs. The ROC curve was conducted in males and females separately due to inherent sex-dependent differences in PEF reference standards. Youden's Index was selected for the optimal cutoff value of the ROC curve. Lastly, we compared the incidences of PPCs between patients who were demarcated by the PEF cutoff value.

\section{Outcomes of Interest}

The primary outcome of interest was the occurrence of PPCs during hospitalization. The secondary endpoints were the length of postsurgical hospitalization (= discharge date - operation date +1$)$ and expense incurred during hospitalization.

\section{Statistical Analysis}

Data were analyzed using SPSS v.23.0 and MedCalc v.15.2.2 software. Continuous variables were presented as the mean with standard deviation (mean $\pm \mathrm{SD}$ ), and categorical variables as proportions (n, \%). In univariate analyses, continuous variables 
were compared by Student's t-test and categorical variables were analyzed using Pearson's chi-squared or Fisher's exact test. Independent risk factors of PPCs were identified by using PEF and other variables with $\mathrm{P}<0.1$ as inputs for a multivariable binary logistic regression model. The discriminative power of PEF on predictions for PPCs was evaluated by ROC analysis, followed by calculation of the area under curve (AUC). All results were considered statistically significant at $\mathrm{P}<0.05$.

\section{RESULTS}

\section{Study Population and Characteristics}

A total of 560 patients who met eligibility criteria were invited to participate in this study, with 104 patients occurred PPCs in 30 days after the operation, who were divided into PPCs group. The baseline characteristics between the two groups are listed in Table 1.

The mean age of patients in the PPCs group was significantly higher than those in the non-PPCs group $(64.6 \pm 8.9$ vs. $61.0 \pm$ $8.6 \mathrm{yr}, \mathrm{P}<0.001)$. Significantly lower PEF $(294.2 \pm 95.7$ vs. $363.0 \pm 105.6 \mathrm{~L} / \mathrm{min}, \mathrm{P}<0.001)$, forced expiratory volume in one second (FEV1; $2.0 \pm 0.6$ vs. $2.4 \pm 0.7 \mathrm{~L}, \mathrm{P}<0.001$ ), and FEV1\% $(86.5 \pm 23.6$ vs. $99.0 \pm 20.8, \mathrm{P}<0.001)$ were found in PPCs group. The proportion of smokers ( $68.3 \%$ vs. $46.2 \%, \mathrm{P}<0.001)$, chronic obstructive pulmonary disease (COPD; $46.9 \%$ vs. $25.1 \%, \mathrm{P}<$ $0.001)$ and open thoracotomy $(39.4 \%$ vs. $20.6 \%, \mathrm{P}<0.001)$ were higher in PPCs group compared to that in non-PPCs group. Additionally, the patients in PPCs group showed significantly longer postoperative stay $(9.8 \pm 4.1$ vs. $5.6 \pm 2.2$ days, $\mathrm{P}<0.001)$ and greater hospitalization expenses $(\$ 9,359 \pm \$ 2,135$ vs. $\$ 7,305 \pm$ $\$ 1,884 ; \mathrm{P}<0.001)$.

\section{Multivariable Analysis of Risk Factors for PPCs}

The variables with $\mathrm{P}<0.1$ in univariate analysis including age, gender, PEF, FEV1, FEV1\%, smoking history, COPD, open thoracotomy and duration of surgery, were included in a multivariable regression model. The multivariable analysis showed that high PEF (OR $=0.991,95 \% \mathrm{CI}$ : 0.988-0.993, P < $0.001)$ was a protective factor. Smoking $(\mathrm{OR}=4.136,95 \% \mathrm{CI}$ : 2.373-7.301, $\mathrm{P}<0.001$ ), video-assisted thoracoscopic surgery $(\mathrm{OR}=0.560,95 \% \mathrm{CI}: 0.329-0.956, \mathrm{P}=0.034)$ and duration of surgery $>3 \mathrm{~h}(\mathrm{OR}=3.903,95 \% \mathrm{CI}: 1.998-7.625, \mathrm{P}<0.001)$ could independently predict the occurrence of PPCs. Univariable and multivariable analyses are shown in Table 2.

\section{ROC Analysis of the Prediction of PEF for PPCs}

The incidence of PPCs with varying distributions of PEF is shown in Figure 1. A trend towards decreasing rate of PPCs with increasing PEF value was observed. The ROC analysis of PEF showed an AUC of 0.711 (95\% CI: 0.639-0.775, P = 0.002) in female patients and an AUC of 0.737 (95\% CI: 0.679-0.790, P < 0.001 ) in male patients for predicting PPCs (Figure 2). According to the ROC curve, a PEF value of $250 \mathrm{~L} / \mathrm{min}$ was selected as the optimal cutoff value for predicting PPCs in the female group (Youden index: 0.364, sensitivity: $65.2 \%$, specificity: $71.3 \%$ ), whilst a PEF value of $320 \mathrm{~L} / \mathrm{min}$ was the cutoff value in the male group (Youden index: 0.356, sensitivity: 57.8\%, specificity: 77.8\%) (Figure 2).

\section{Comparisons Between Patients Demarcated by PEF Cutoff Value Female Group}

Among 245 female patients, $\mathrm{PEF} \leq 250 \mathrm{~L} / \mathrm{min}$ was confirmed in 75 patients (ratio $=30.6 \%$ ). Patients in $\mathrm{PEF} \leq 250 \mathrm{~L} / \mathrm{min}$ group was older $(65.4 \pm 7.8$ vs. $59.3 \pm 8.9 \mathrm{yr}, \mathrm{P}<0.001)$ and had worse physical conditions. Their pulmonary function indicators of FEV1 and FEV1\% were significantly lower than those of patients in $\mathrm{PEF}>250 \mathrm{~L} / \mathrm{min}$ group. Moreover, a higher percentage of diabetes, hypertension, and COPD were found in $\mathrm{PEF} \leq 250 \mathrm{~L} / \mathrm{min}$ group. With regard to clinical outcomes, patients with $\mathrm{PEF} \leq 250 \mathrm{~L} / \mathrm{min}$ had longer postoperative stay (7.0 \pm 3.1 vs. $5.5 \pm 2.7$ days, $\mathrm{P}=0.001)$ and higher hospitalization expenses ( $\$ 7,704 \pm \$ 2,136 v s$. $\$ 7,117 \pm \$ 2,075, P=0.045)$, drug costs $(\$ 1,228 \pm 568$ vs. $\$ 977 \pm 499, \mathrm{P}=0.001)$, and PPCs rate (30.7\% vs. $8.2 \%, \mathrm{P}<0.001)$ (Table 3 ).

\section{Male Group}

Of the 315 male patients, $\mathrm{PEF} \leq 320 \mathrm{~L} / \mathrm{min}$ was confirmed in 96 patients. Patients in $\mathrm{PEF} \leq 320 \mathrm{~L} / \mathrm{min}$ group were older (mean age, $64.7 \pm 8.3$ vs. $60.8 \pm 8.8 \mathrm{yr}, \mathrm{P}<0.001$ ), comprised a higher proportion of cases of COPD $(66.7 \%$ vs. $21.5 \%, \mathrm{P}<0.001)$, and had poorer lung function, compared to the PEF $>320 \mathrm{~L} / \mathrm{min}$ group; however, there were no differences in diabetes and hypertension. Further, with regard to clinical outcomes, patients with $\mathrm{PEF} \leq 320 \mathrm{~L} / \mathrm{min}$ had significantly prolonged postoperative stay $(8.8 \pm 3.9$ vs. $6.9 \pm 3.1$ days, $\mathrm{P}=0.001)$, higher hospitalization costs $(\$ 8,294 \pm \$ 2,174$ vs. $\$ 7,804 \pm \$ 1,926$, $c<0.001)$ and drug costs $(\$ 1,726 \pm \$ 699$ vs. $\$ 1,299 \pm \$ 582$, $\mathrm{P}<0.001)$, higher rate of PPCs $(40.6 \%$ vs. $12.8 \%, \mathrm{P}<0.001)$, which were mainly due to significant differences of pneumonia (31.3\% vs. $9.1 \%, \mathrm{P}<0.001)$ and air leak $(12.5 \%$ vs. $5.5 \%, \mathrm{P}=$ 0.031) (Table 4).

\section{DISCUSSION}

Pulmonary complications are the principal factors affecting postoperative rehabilitation of lung cancer patients. In addition to optimizing the perioperative process, key objectives of postoperative rapid lung rehabilitation are the prevention and reduction of postoperative pulmonary complications. Therefore, the first step to promote rapid postoperative recovery of lung cancer patients is to identify and evaluate the risk factors of PPCs that enable reasonable intervention. These risk factors vary due to inconsistent definitions and standards of PPCs in various studies, differences in inclusion and exclusion criteria, ethnic and cultural differences, and treatment of complications. Advanced age, smoking history, COPD and reduced lung function have been consistently identified as risk factors in several studies (14-16). 
TABLE 1 | Baseline and clinical characteristics between the PPCs groups and non-PPCs group.

\begin{tabular}{|c|c|c|c|}
\hline Variables & PPCs group $(n=104)$ & non-PPCs group $(n=456)$ & $P$-value \\
\hline Age (years), mean \pm SD & $64.6 \pm 8.9$ & $61.0 \pm 8.6$ & $<0.001$ \\
\hline $\mathrm{BMI}\left(\mathrm{kg} / \mathrm{m}^{2}\right)$, mean $\pm \mathrm{SD}$ & $23.3 \pm 3.1$ & $23.4 \pm 2.9$ & 0.667 \\
\hline Gender, $n(\%)$ & & & 0.063 \\
\hline Male & $67(64.4 \%)$ & 248 (54.4\%) & \\
\hline Female & $37(35.6 \%)$ & $208(45.6 \%)$ & \\
\hline \multicolumn{4}{|l|}{ Pulmonary function, mean \pm SD } \\
\hline PEF (L/min) & $294.2 \pm 95.7$ & $363.0 \pm 105.6$ & $<0.001$ \\
\hline FEV1 (L) & $2.0 \pm 0.6$ & $2.4 \pm 0.7$ & $<0.001$ \\
\hline FEV $1 \%$ & $86.5 \pm 23.6$ & $99.0 \pm 20.8$ & $<0.001$ \\
\hline Smoking status, $n$ (\%) & & & $<0.001$ \\
\hline Current or former smokers & $71(68.3 \%)$ & $210(46.1 \%)$ & \\
\hline Non-smokers & $33(31.7 \%)$ & 246 (53.9\%) & \\
\hline \multicolumn{4}{|l|}{ Comorbidities, $n(\%)$} \\
\hline Diabetes & 15 (14.4\%) & 49 (10.7\%) & 0.287 \\
\hline Hypertension & $30(28.8 \%)$ & $120(26.3 \%)$ & 0.599 \\
\hline COPD & 46 (46.9\%) & $105(25.1 \%)$ & $<0.001$ \\
\hline Surgical approach, $n$ (\%) & & & $<0.001$ \\
\hline Open & 41 (39.4\%) & 94 (20.6\%) & \\
\hline VATS & $63(60.6 \%)$ & 362 (79.4\%) & \\
\hline Resection type, $n$ (\%) & & & 0.002 \\
\hline Lobectomy & 78 (75.0\%) & 267 (58.6\%) & \\
\hline Sublobar resection & $26(25.0 \%)$ & $189(41.4 \%)$ & \\
\hline Operation time (min), mean \pm SD & $142.7 \pm 49.6$ & $112.4 \pm 47.2$ & $<0.001$ \\
\hline Pathological type, $n$ (\%) & & & 0.123 \\
\hline Adenocarcinoma & $56(53.9 \%)$ & $286(62.7 \%)$ & \\
\hline Squamous carcinoma & $33(31.7 \%)$ & $102(22.4 \%)$ & \\
\hline Other NSCLC & $15(14.4 \%)$ & $68(14.9 \%)$ & \\
\hline Pathological stage, $n$ (\%) & & & 0.712 \\
\hline Stage I & $59(56.7 \%)$ & $276(60.5 \%)$ & \\
\hline Stage ॥ & $26(25.0 \%)$ & $98(21.5 \%)$ & \\
\hline Stage III+IV & 19 (18.3\%) & $82(18.0 \%)$ & \\
\hline Postoperative stay, mean \pm SD & $9.8 \pm 4.1$ & $5.6 \pm 2.2$ & $<0.001$ \\
\hline Hospitalization expenses (\$), mean \pm SD & $9,359 \pm 2,134$ & $7,305 \pm 1,884$ & $<0.001$ \\
\hline
\end{tabular}

BMI, body mass index; PEF, peak expiratory flow; FEV1, forced expiratory volume in 1 second; COPD, chronic obstructive pulmonary disease; VATS, video-assisted thoracoscopic surgery; NSCLC, non-small cell lung cancer.

TABLE 2 | Univariate and multivariable analysis for risk factors of PPCs.

\begin{tabular}{|c|c|c|c|c|c|c|c|}
\hline \multirow[t]{2}{*}{ Variables } & \multirow[t]{2}{*}{ Category } & \multicolumn{3}{|c|}{ Univariate analysis } & \multicolumn{3}{|c|}{ Multivariable analysis } \\
\hline & & OR & $95 \% \mathrm{Cl}$ & $P$-value & OR & $95 \% \mathrm{Cl}$ & $P$-value \\
\hline Age & $<70, \geq 70$ & 2.089 & $1.291-3.380$ & 0.003 & 1.746 & $0.951-3.205$ & 0.072 \\
\hline Gender & $\mathrm{F}, \mathrm{M}$ & 1.519 & $0.976-2.362$ & 0.064 & 0.469 & $0.162-1.359$ & 0.163 \\
\hline PEF & Per unit increase & 0.993 & $0.990-0.995$ & $<0.001$ & 0.991 & 0.987-0.995 & $<0.001$ \\
\hline PEF(male) & $\geq 320,<320$ & 4.667 & $2.643-8.241$ & $<0.001$ & - & - & - \\
\hline PEF(female) & $\geq 250,<250$ & 4.929 & $2.364-10.276$ & $<0.001$ & - & - & - \\
\hline FEV1 & Per unit increase & 0.438 & $0.306-0.627$ & $<0.001$ & 1.392 & $0.718-2.698$ & 0.328 \\
\hline FEV1\% & $\geq 70,<70$ & 4.170 & $2.429-7.159$ & $<0.001$ & 2.145 & 0.957-4.809 & 0.064 \\
\hline Lobectomy & Yes & 2.124 & $1.132-3.437$ & 0.002 & 1.604 & $0.918-2.803$ & 0.097 \\
\hline Smoking status & Yes & 2.510 & $1.597-3.945$ & $<0.001$ & 5.457 & $1.980-15.038$ & 0.001 \\
\hline Diabetes & Yes & 1.400 & $0.751-2.608$ & 0.289 & - & - & - \\
\hline Hypertension & Yes & 1.135 & $0.708-1.821$ & 0.599 & - & - & - \\
\hline COPD & Yes & 2.637 & $1.674-4.153$ & $<0.001$ & 1.198 & $0.642-2.235$ & 0.570 \\
\hline VATS procedure & Yes & 0.399 & $0.253-0.628$ & $<0.001$ & 0.542 & 0.316-0.929 & 0.026 \\
\hline Operation time & $<3 \mathrm{~h}, \geq 3 \mathrm{~h}$ & 2.805 & $1.582-4.974$ & $<0.001$ & 3.529 & $1.840-6.769$ & $<0.001$ \\
\hline
\end{tabular}

PEF, peak expiratory flow; FEV1, forced expiratory volume in 1 second; COPD, chronic obstructive pulmonary disease; VATS, video-assisted thoracoscopic surgery.

Prior to surgery, examination of pulmonary function aids in assessing the risk of pulmonary surgery $(17,18)$. The perioperative utility of PEF remains debatable since it is mostly used for the diagnosis and follow-up of asthma (19), with relatively few applications in pulmonary surgery. A significant finding of our study was that low PEF values independently predicted the occurrence of PPCs for lung cancer patients undergoing resection. Both female and male patients with PEF under cutoff 


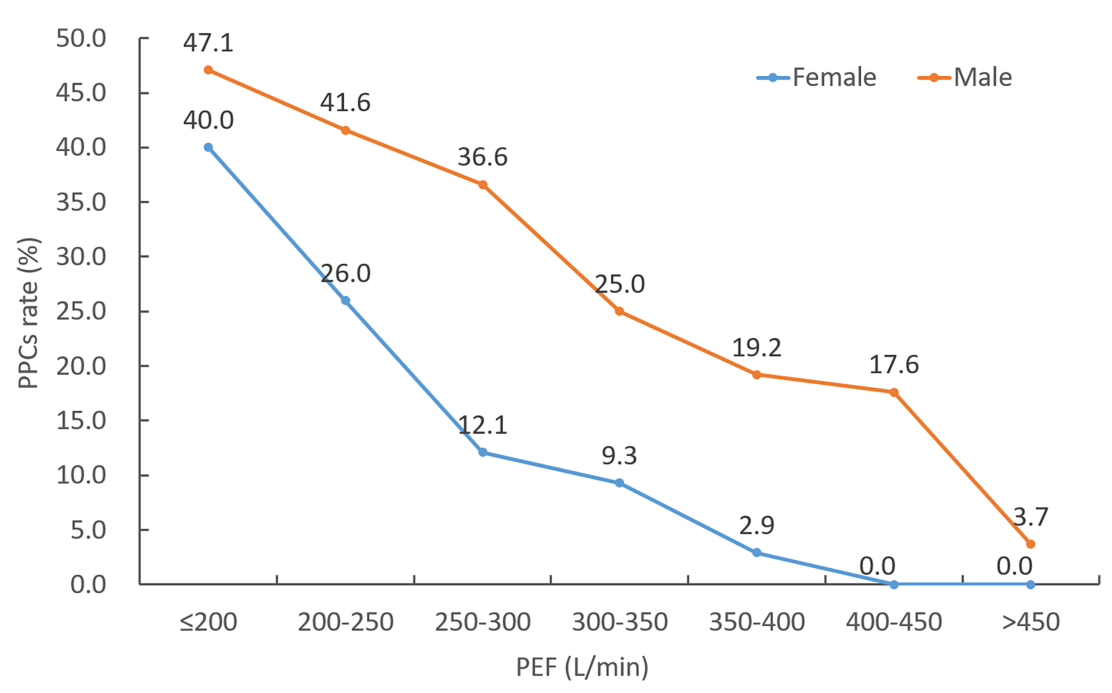

FIGURE 1 | The incidence of PPCs in different ranges of PEF.

A

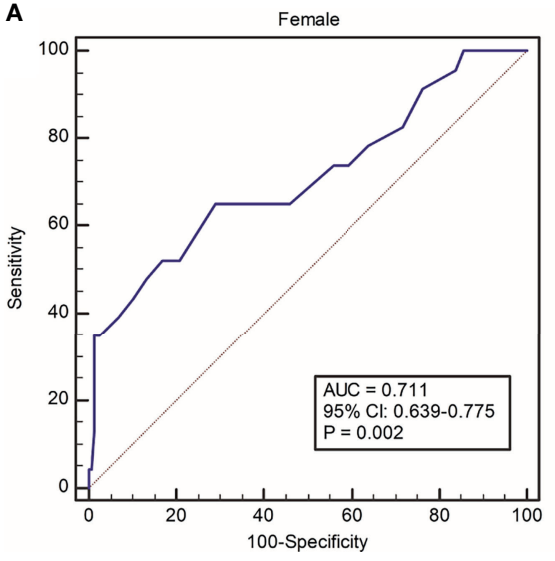

B

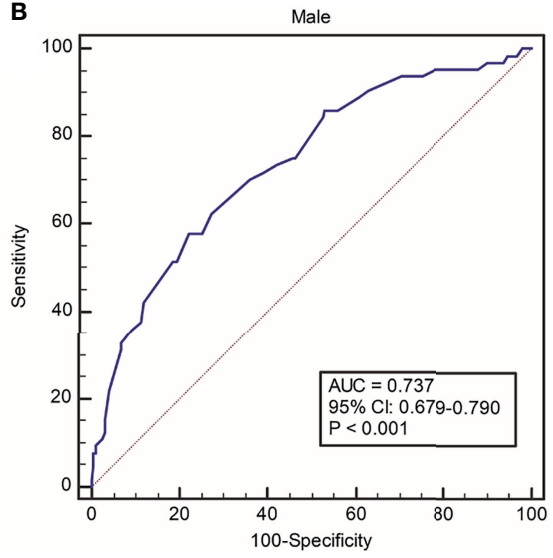

FIGURE 2 | ROC analysis on discriminative power of PEF for predicting risk of PPCs in (A) female and (B) male groups.

value reported adverse clinical outcomes, including higher PPCs rate, prolonged length of stay, and increased hospital costs.

The respiratory muscles force and the severity of airway obstruction are closely related to PEF, which can be measured easily, using a portable mechanical or electronic flow meter that is easy to operate and cost-effective. It can be used at home or by the patient's bedside and only requires the examinee to exhale quickly and forcefully. The process of detecting PEF is similar to coughing, wherein rapid and powerful contraction of the diaphragm and abdominal muscle increase intra-abdominal pressure. Since abdominal contents are virtually incompressible, the volume of the abdominal cavity changes little. The diaphragm then lifts and compresses the chest cavity, and the intercostal muscle retracts, rapidly reducing the volume of the chest cavity, extruding lungs to form high-pressure gas resulting in rapid exhalation (20). Cough is an effective self-protection method for clearing respiratory secretions, and it is also an essential auxiliary means to eliminate pleural effusion and pneumatosis after lung surgery $(8,21)$. In recent years, advances in and popularity of thoracoscopic surgery has reduced surgical chest wall trauma, but patients with weak respiratory muscles strength who have had lung resection exhibit clinical issues such as poor coughing ability and efficiency, resulting in sputum retention that leads to pulmonary complications. Additionally, lung cancer patients with COPD reach up to $40 \%$ $70 \%$. These patients have hypersecretion of mucous glands in the respiratory tract. Meanwhile, the anesthetic drugs and tracheal intubation stimulation could increase airway secretions. The combined effect of coughing impairment and hypersecretion of airway increases the risk of pulmonary infection (22). 
TABLE 3 | Clinical characteristics and outcomes between female patients divided by cutoff value of PEF.

\begin{tabular}{|c|c|c|c|}
\hline Variables & $\mathrm{PEF} \leq 250 \mathrm{~L} / \mathrm{min}(n=75)$ & PEF $>250 \mathrm{~L} / \min (n=170)$ & $P$-value \\
\hline Age (years), mean \pm SD & $65.4 \pm 7.8$ & $59.3 \pm 8.9$ & $<0.001$ \\
\hline $\mathrm{BMI}\left(\mathrm{kg} / \mathrm{m}^{2}\right)$, mean $\pm \mathrm{SD}$ & $23.6 \pm 3.5$ & $23.1 \pm 2.9$ & 0.297 \\
\hline \multicolumn{4}{|l|}{ Pulmonary function, mean \pm SD } \\
\hline PEF (L/min) & $214.1 \pm 37.8$ & $337.7 \pm 50.8$ & $<0.001$ \\
\hline FEV1 (L) & $1.6 \pm 0.4$ & $2.1 \pm 0.4$ & $<0.001$ \\
\hline FEV1\% & $91.6 \pm 24.1$ & $108.4 \pm 18.3$ & $<0.001$ \\
\hline Smoking history, $n$ (\%) & $6(8.0 \%)$ & $6(3.5 \%)$ & 0.138 \\
\hline \multicolumn{4}{|l|}{ Comorbidities, $n(\%)$} \\
\hline Diabetes & $13(17.3 \%)$ & $13(7.6 \%)$ & 0.023 \\
\hline Hypertension & 29 (38.7\%) & 39 (22.9\%) & 0.011 \\
\hline COPD & $28(40.6 \%)$ & $12(7.1 \%)$ & $<0.001$ \\
\hline Surgical approach, $n$ (\%) & & & 0.164 \\
\hline Open & $18(24.0 \%)$ & $28(16.5 \%)$ & \\
\hline VATS & 57 (76.0\%) & 142 (83.5\%) & \\
\hline Operation time $(\mathrm{min})$, mean $\pm \mathrm{SD}$ & $123.4 \pm 46.8$ & $113.3 \pm 47.2$ & 0.123 \\
\hline Postoperative stay, mean \pm SD & $7.0 \pm 3.1$ & $5.5 \pm 2.7$ & 0.001 \\
\hline Hospitalization expenses (\$), mean \pm SD & $7,704 \pm 2136$ & $7,117 \pm 2,075$ & 0.045 \\
\hline Drug cost $(\$)$, mean \pm SD & $1,228 \pm 568$ & $977 \pm 499$ & 0.001 \\
\hline PPCs rate, $n(\%)$ & $23(30.7 \%)$ & $14(8.2 \%)$ & $<0.001$ \\
\hline Pneumonia & 15 (20.0\%) & $9(5.4 \%)$ & $<0.001$ \\
\hline Atelectasis & $6(8.0 \%)$ & $5(2.9 \%)$ & 0.153 \\
\hline Air leak & $3(4.0 \%)$ & $4(2.4 \%)$ & 0.766 \\
\hline Pneumothorax & $1(1.3 \%)$ & $3(1.8 \%)$ & 0.763 \\
\hline Pleural effusion & $0(0.0 \%)$ & $2(1.2 \%)$ & 1.000 \\
\hline Mechanical ventilation $>48 \mathrm{~h}$ & $1(1.3 \%)$ & $0(0.0 \%)$ & 1.000 \\
\hline Bronchopleural fistula & $0(0.0 \%)$ & $0(0.0 \%)$ & 1.000 \\
\hline Pulmonary embolism & $0(0.0 \%)$ & $1(0.6 \%)$ & 1.000 \\
\hline
\end{tabular}

BMI, body mass index; PEF, peak expiratory flow; FEV1, forced expiratory volume in 1 second; COPD, chronic obstructive pulmonary disease; VATS, video-assisted thoracoscopic surgery.

TABLE 4 | Clinical characteristics and outcomes between male patients divided by cutoff value of PEF.

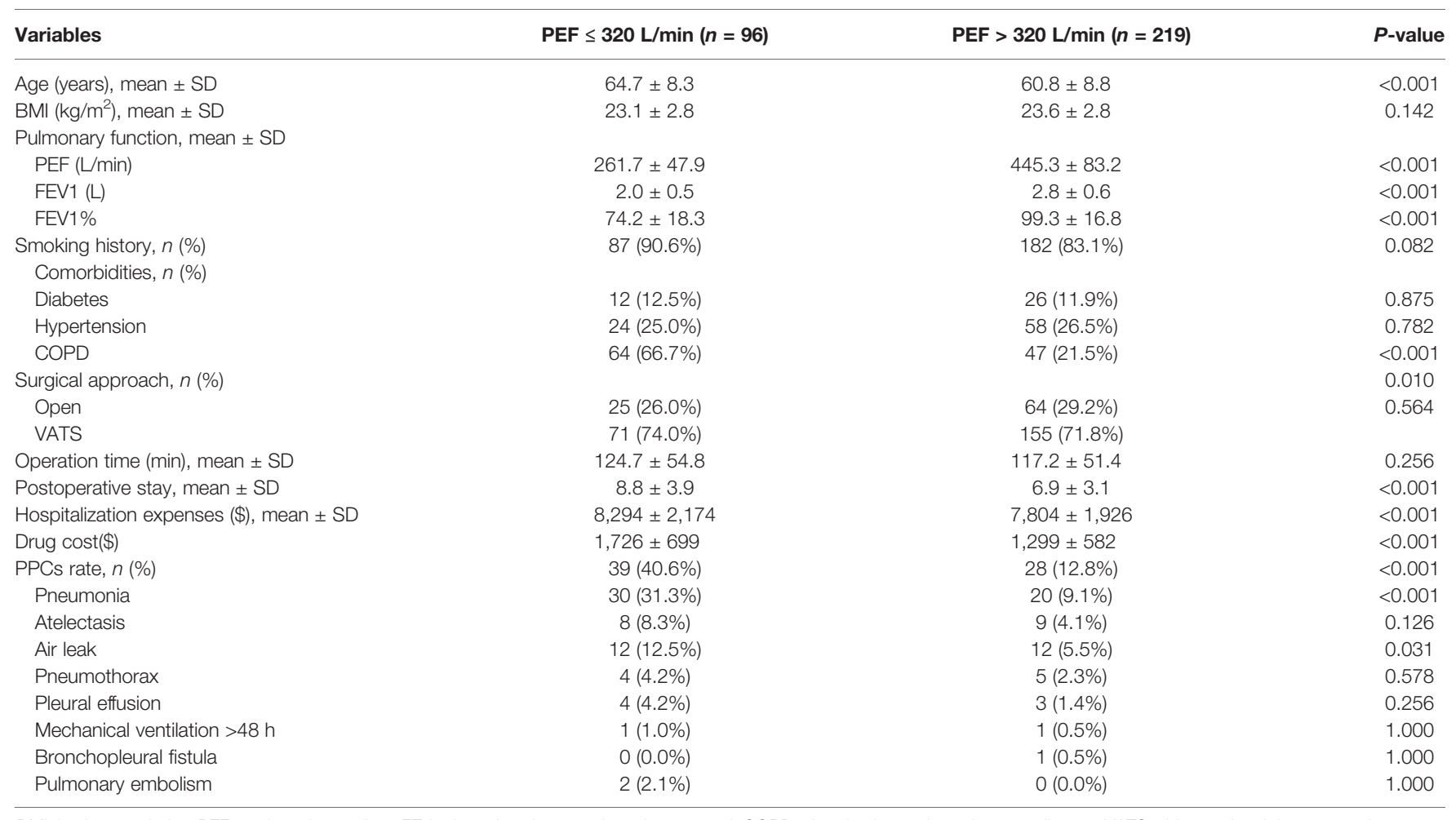

BMI, body mass index; PEF, peak expiratory flow; FEV1, forced expiratory volume in 1 second; COPD, chronic obstructive pulmonary disease; VATS, video-assisted thoracoscopic surgery. 
Prior to our study, the correlation between PEF and PPCs was controversial. The British Thoracic Society guideline for the physiotherapy management of the spontaneously breathing patient suggests that when the PEF of patients with neuromuscular disease equal to or less than $270 \mathrm{ml} / \mathrm{L}$, the strategies for assisted airway clearance should be used (23). Kulnik et al. found that the strong cough (with high peak cough flow) could protect from aspiration-related pneumonia in patients with stroke and swallowing problems (24). However, Colucci and colleagues drew a negative conclusion that there was no association between the PEF and PPCs in patients who underwent open upper abdominal surgery (8). Our results showed that the PEF of surgical lung cancer patients with PPCs was significantly lower compared to those without PPCs, and low PEF was an independent risk factor for PPCs in the multivariable analysis. We recommend separate gender-based analysis of PEF since it is significantly affected by skeletal muscle strength. The ROC curve calculated that the optimal cutoff value for predicting PPC by PEF was $320 \mathrm{~L} / \mathrm{min}$ for male patients and $250 \mathrm{~L} / \mathrm{min}$ for female patients. If the PEF was lower than the cutoff values, PPCs were significantly likely to occur after surgery, both in male and female patients, compared to patients with PEF higher than the cutoff value. Meanwhile, postoperative hospitalization days and hospitalization costs were significantly higher in the low PEF group, compared to high PEF group. Our study provides a new perspective for screening high-risk patients before lung cancer surgery based on these results. Ishida et al. reported that the thickness of the external oblique muscle might be associated with PEF (20), which may help in improving PEF, through such exercise training modalities as oblique crunch and side bridge. These related exercises could be considered as a part of pulmonary rehabilitation program to enhance the respiratory strength and cough efficiency.

\section{Limitations}

This study is not without certain limitations. First, there is no standard definition of PPCs, which may have led to biased results. Second, since all lung cancer resections were performed at a single center, the general applicability of our findings is limited. Third, the variability and accuracy of PEF is closely related to skill proficiency and different spirometers, which requires the technician to strictly check data collection to ensure the authenticity and stability of data. Fourth, the PEF cutoff values in this study were measured in Asians only, thus the

\section{REFERENCES}

1. Siegel RL, Miller KD, Jemal A. Cancer Statistics, 2020. CA Cancer J Clin (2020) 70:7-30. doi: 10.3322/caac.21590

2. David EA, Andersen SW, Beckett LA, Melnikow J, Clark JM, Brown LM, et al. Survival Benefits Associated With Surgery for Advanced non-Small Cell Lung Cancer.J Thorac Cardiovasc Surg (2019) 157:1620-28. doi: 10.1016/j.jtcvs.2018.10.140

3. Agostini P, Cieslik H, Rathinam S, Bishay E, Kalkat MS, Rajesh PB, et al. Postoperative Pulmonary Complications Following Thoracic Surgery: Are generalizability of the results to other races will need investigation. Our results need to be confirmed in prospective studies at multiple centers and with large sample sizes.

\section{CONCLUSIONS}

Our prospective cohort study demonstrated that low PEF serves as an independent risk predictor of PPCs for lung cancer patients undergoing lobectomy and segmentectomy. Therefore, considering PEF cutoff value in the perioperative risk assessment for lung cancer patients may be of benefit.

\section{DATA AVAILABILITY STATEMENT}

The raw data supporting the conclusions of this article will be made available by the authors, without undue reservation.

\section{ETHICS STATEMENT}

The studies involving human participants were reviewed and approved by Regional Ethics Committee of Sichuan University West China Hospital (No. 2016-121). The registration number was ChiCTR-COC-17010720, which was obtained from the Chinese Clinical Trial Registry. The study adhered to the tenets of the Declaration of Helsinki. The patients/participants provided their written informed consent to participate in this study.

\section{AUTHOR CONTRIBUTIONS}

GC, YW, and YL contributed to the conception, design of the study. SC and KZ contributed equally as first authors. All authors contributed to the intellectual conception revision of important intellectual content, and approval of the final version of this manuscript.

\section{FUNDING}

This study was supported by Chengdu Science and Technology Support Program (2019-YF05-00373-SN).

There Any Modifiable Risk Factors? Thorax (2010) 65:815-8. doi: 10.1136/ thx.2009.123083

4. Brunelli A, Drosos P, Dinesh P, Ismail H, Bassi V. The Severity of Complications Is Associated With Postoperative Costs After Lung Resection. Ann Thorac Surg (2017) 103:1641-46. doi: 10.1016/ j.athoracsur.2016.10.061

5. Brunelli A, Al Refai M, Monteverde M, Borri A, Salati M, Fianchini A. Stair Climbing Test Predicts Cardiopulmonary Complications After Lung Resection. Chest (2002) 121:1106-10. doi: 10.1378/chest.121.4.1106 
6. Licker MJ, Widikker I, Robert J, Frey JG, Spiliopoulos A, Ellenberger C, et al. Operative Mortality and Respiratory Complications After Lung Resection for Cancer: Impact of Chronic Obstructive Pulmonary Disease and Time Trends. Ann Thorac Surg (2006) 81:1830-7. doi: 10.1016/j.athoracsur.2005.11.048

7. Stephan F, Boucheseiche S, Hollande J, Flahault A, Cheffi A, Bazelly B, et al. Pulmonary Complications Following Lung Resection: A Comprehensive Analysis of Incidence and Possible Risk Factors. Chest (2000) 118:1263-70. doi: $10.1378 /$ chest.118.5.1263

8. Colucci DB, Fiore JFJr., Paisani DM, Risso TT, Colucci M, Chiavegato LD, et al. Cough Impairment and Risk of Postoperative Pulmonary Complications After Open Upper Abdominal Surgery. Respir Care (2015) 60:673-8. doi: $10.4187 /$ respcare. 03600

9. Smina M, Salam A, Khamiees M, Gada P, Amoateng-Adjepong Y, Manthous CA. Cough Peak Flows and Extubation Outcomes. Chest (2003) 124:262-8. doi: $10.1378 /$ chest.124.1.262

10. Goldstraw P, Chansky K, Crowley J, Rami-Porta R, Asamura H, Eberhardt WE, et al. The IASLC Lung Cancer Staging Project: Proposals for Revision of the TNM Stage Groupings in the Forthcoming (Eighth) Edition of the TNM Classification for Lung Cancer. J Thorac Oncol (2016) 11:39-51. doi: 10.1016/ j.jtho.2015.09.009

11. Seely AJ, Ivanovic J, Threader J, Al-Hussaini A, Al-Shehab D, Ramsay T, et al. Systematic Classification of Morbidity and Mortality After Thoracic Surgery. Ann Thorac Surg (2010) 90:936-42; discussion 42. doi: 10.1016/ j.athoracsur.2010.05.014

12. Fernandez FG, Falcoz PE, Kozower BD, Salati M, Wright CD, Brunelli A. The Society of Thoracic Surgeons and the European Society of Thoracic Surgeons General Thoracic Surgery Databases: Joint Standardization of Variable Definitions and Terminology. Ann Thorac Surg (2015) 99:368-76. doi: 10.1016/j.athoracsur.2014.05.104

13. Miskovic A, Lumb AB. Postoperative Pulmonary Complications. Br J Anaesth (2017) 118:317-34. doi: 10.1093/bja/aex002

14. Gallart L, Canet J. Post-Operative Pulmonary Complications: Understanding Definitions and Risk Assessment. Best Pract Res Clin Anaesthesiol (2015) 29:315-30. doi: 10.1016/j.bpa.2015.10.004

15. Husain ZA, Kim AW, Yu JB, Decker RH, Corso CD. Defining the High-Risk Population for Mortality After Resection of Early Stage NSCLC. Clin Lung Cancer (2015) 16:e183-7. doi: 10.1016/j.cllc.2015.04.007

16. Simonsen DF, Sogaard M, Bozi I, Horsburgh CR, Thomsen RW. Risk Factors for Postoperative Pneumonia After Lung Cancer Surgery and Impact of Pneumonia on Survival. Respir Med (2015) 109:1340-6. doi: 10.1016/ j.rmed.2015.07.008

17. Brunelli A, Kim AW, Berger KI, Addrizzo-Harris DJ. Physiologic Evaluation of the Patient With Lung Cancer Being Considered for Resectional Surgery: Diagnosis and Management of Lung Cancer, 3rd Ed: American College of
Chest Physicians Evidence-Based Clinical Practice Guidelines. Chest (2013) 143:e166S-e90S. doi: 10.1378/chest.12-2395

18. Bobbio A, Chetta A, Carbognani P, Internullo E, Verduri A, Sansebastiano G, et al. Changes in Pulmonary Function Test and Cardio-Pulmonary Exercise Capacity in COPD Patients After Lobar Pulmonary Resection. Eur J Cardiothorac Surg (2005) 28:754-8. doi: 10.1016/j.ejcts.2005.08.001

19. Paton JY. Perception of Lung Function, Adherence to Inhaled Corticosteroids, and the Role of Peak Expiratory Flow Feedback in Paediatric Asthma. Thorax (2012) 67:1023-4. doi: 10.1136/thoraxjnl-2012-202244

20. Ishida H, Kobara K, Osaka H, Suehiro T, Ito T, Kurozumi C, et al. Correlation Between Peak Expiratory Flow and Abdominal Muscle Thickness. J Phys Ther Sci (2014) 26:1791-3. doi: 10.1589/jpts.26.1791

21. Sancho J, Servera E, Díaz J, Marín J. Comparison of Peak Cough Flows Measured by Pneumotachograph and a Portable Peak Flow Meter. Am J Phys Med Rehabil (2004) 83:608-12. doi: 10.1097/01.PHM.0000133431.70907.A2

22. Young RP, Hopkins RJ, Christmas T, Black PN, Metcalf P, Gamble GD. COPD Prevalence Is Increased in Lung Cancer, Independent of Age, Sex and Smoking History. Eur Respir J (2009) 34:380-6. doi: 10.1183/ 09031936.00144208

23. Bott J, Blumenthal S, Buxton M, Ellum S, Falconer C, Garrod R, et al Guidelines for the Physiotherapy Management of the Adult, Medical, Spontaneously Breathing Patient. Thorax (2009) 64 Suppl 1:i1-51. doi: 10.1136/thx.2008.110726

24. Kulnik ST, Birring SS, Hodsoll J, Moxham J, Rafferty GF, Kalra L. Higher Cough Flow Is Associated With Lower Risk of Pneumonia in Acute Stroke. Thorax (2016) 71:474-75. doi: 10.1136/thoraxjnl-2015-207810

Conflict of Interest: The authors declare that the research was conducted in the absence of any commercial or financial relationships that could be construed as a potential conflict of interest.

Publisher's Note: All claims expressed in this article are solely those of the authors and do not necessarily represent those of their affiliated organizations, or those of the publisher, the editors and the reviewers. Any product that may be evaluated in this article, or claim that may be made by its manufacturer, is not guaranteed or endorsed by the publisher.

Copyright (c) 2021 Chang, Zhou, Wang, Lai and Che. This is an open-access article distributed under the terms of the Creative Commons Attribution License (CC BY). The use, distribution or reproduction in other forums is permitted, provided the original author(s) and the copyright owner(s) are credited and that the original publication in this journal is cited, in accordance with accepted academic practice. No use, distribution or reproduction is permitted which does not comply with these terms. 